Bull. Mater, Sci, Vol. 4, No. 5, December 1982, pp. 595-601, (C) Printed in India.

\title{
Flow stress of an aluminium alloy in the warm working range
}

\author{
S K PACHISIA, S K RAMALINGAM and \\ MALUR N SRINIVASAN \\ Department of Mechanical Engineering, Indian Institute of Science, Bangalore 560012 , \\ India
}

MS received 15 February 1982

\begin{abstract}
The effect of temperature and processing history on the flow stress of a two-phase aluminium $(\mathrm{Al}-6 \% \mathrm{Cu})$ alloy was investigated. The flow stress was determined from the changes in dimensions of flat, ring-shaped specimens using Avitzur's upper bound theorem. The results indicate that the flow stress increases with the degree of deformation irrespective of the specimen history considered and this tendency is in general more pronounced at large deformations. The flow stress of this alloy at large deformation is considerably lower at $573 \mathrm{~K}$ than at the lower temperatures tested. The morphology and distribution of the second phase particles of this alloy changed considerably depending upon the processing history, temperature and deformation.
\end{abstract}

Keywords. Flow stress; warm working; aluminium alloy; spheroidization ; metal forming; deformation.

\section{Introduction}

A clear understanding of the force requirements in metal-forming operations would lead to obvious technical and economic advantages. But this force is affected both by macroscopic variables like the geometry of the work piece and microscopic variations, e.g., dislocation density. Solid mechanics ignores the latter set of variables while macro-level behaviour cannot be easily predicted by considerations involving dislocation dynamics. It is not surprising therefore that industry often relies on rules of thumb (Berry and Pope 1971) to arrive at the deformation force. As the flow stress of a material is affected by both microscopic and macroscopic variables, its evaluation under controlled conditions and subsequent use in mathematical models for prediction of forming loads will thus considerably improve the situation. Correlation of the flow stress with the experimental variables would also improve understanding of the material behaviour under such conditions.

Warm working of alloys will minimise oxidation and contamination as compared to hot working, while at the same time, requiring lower forming loads compared to room temperature operations. However the optimum warm working range can only be established after unders tanding, among other things, 
the behaviour of the flow stress as affected by temperature and processing conditions representative of metal forming operations. As aluminium- $6 \%$ copper alloy forms the basis of some commercially important wrought alloys, this was chosen initially for study. Further, it is known that spheroidizing the second phase particles may lead to significant changes in mechanical behaviour (Ashok and Charles 1979) and thus this treatment was chosen as variables for this study.

The determination of flow stress in this study is based on the analysis of Avitzur (1968) applied to determine flow stress by Saul et al (1971). Avitzur solved the problem of axial compression of flat ring-shaped specimens placed between flat dies, by using an upper bound technique.

The results of Saul et al (1971) indicate that under low friction conditions specimens of initial geometric ratio $6: 3: 1$ (OD :ID : thickness) are adequate for applying Avitzur's analysis. Accordingly this ratio was maintained in the present work.

Although the Polakowski (1949) technique is very accurate, it is tedious to perform and can only be used effectively at low strain rates and ambient temperature (Saul et al 1971). On the other hand the present method developed by Saul et al (1971) has been shown to be conducive to the generation of realistic flow stress data under conditions typical of many metal forming operations.

\section{Experimental}

Ring specimens (19 mm OD, $9.5 \mathrm{~mm} \mathrm{ID,} \mathrm{and} 3.2 \mathrm{~mm}$ thickness) were machined from chill-cast bars of aluminium- $6 \%$ copper alloy, prepared from commercial purity aluminium and OFHC copper. The specimens were divided into three batches. While one batch was subjected to compression without prior treatment, the second and third batches were given spheroidization treatments before compression. The treatments involved soaking in a muffle furnace at $700 \mathrm{~K}$ for $24 \mathrm{hr}$ and $36 \mathrm{hr}$ respectively, before cooling in the furnace. The specimens were compressed between flat faces of dies in a $500 \mathrm{KN}$ compression testing machine. The dies were lubricated with graphite disparsed in a solution of sodium silicate in water. The temperature of the dies along with the specimen was maintained at different levels using a tubular resistance furnace provided with a blind temperature controller. The initial and final values of the inner and outer diameters of the rings were measured using a vernier travelling microscope. For microstructural examination, small pieces cut from the compressed rings were ground, polished, etched with $0.5 \%$ hydrofluoric acid and examined in a metallurgical microscope.

\section{Results and discussion}

A computer program was written to solve Avitzur's equations to determine the flow stress for different incremental deformations at various temperature levels. Figures 1 to 3 , which give these values under different conditions, indicate that the values of the flow stress of the alloy at large deformations were considerably lower at $573 \mathrm{~K}$ than at other temperatures, irrespective of the specimen 
history. Further, in general the tendency of the flow stress to rise with respect to deformation increases when the deformation exceeds about $50 \%$. This behaviour, under the experimental conditions, may be promoted by two factors. The first factor is the possibility of frictional effects being underestimated in Avitzur's analysis, while the second corresponds to structural features unfavourable to the flow of the material. Additional experiments performed with unlubricated specimens, and specimens with different thicknesses did not indicate appreciable differences in the above trend. Thus it is very likely that structural features are predominantly responsible for the observed behaviour in the flow stress.

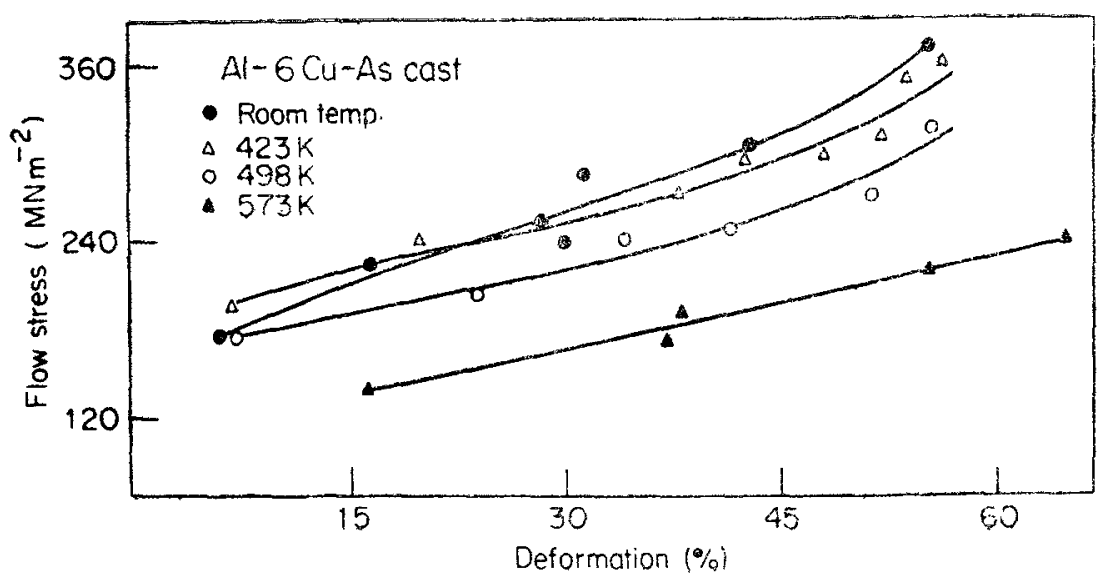

Fig. 1

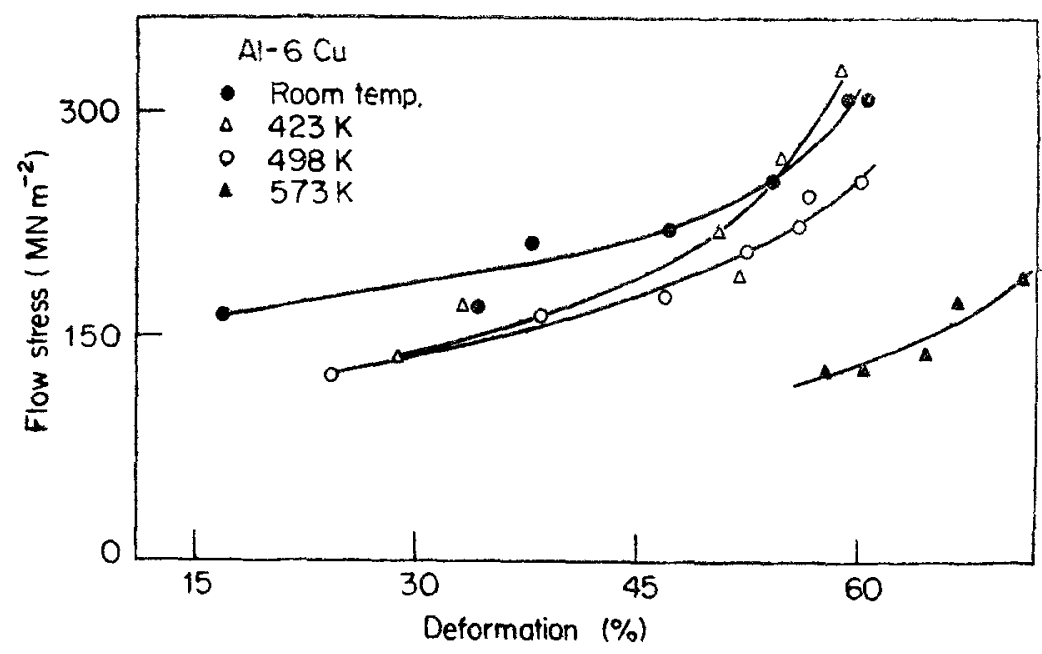

Fig. 2 


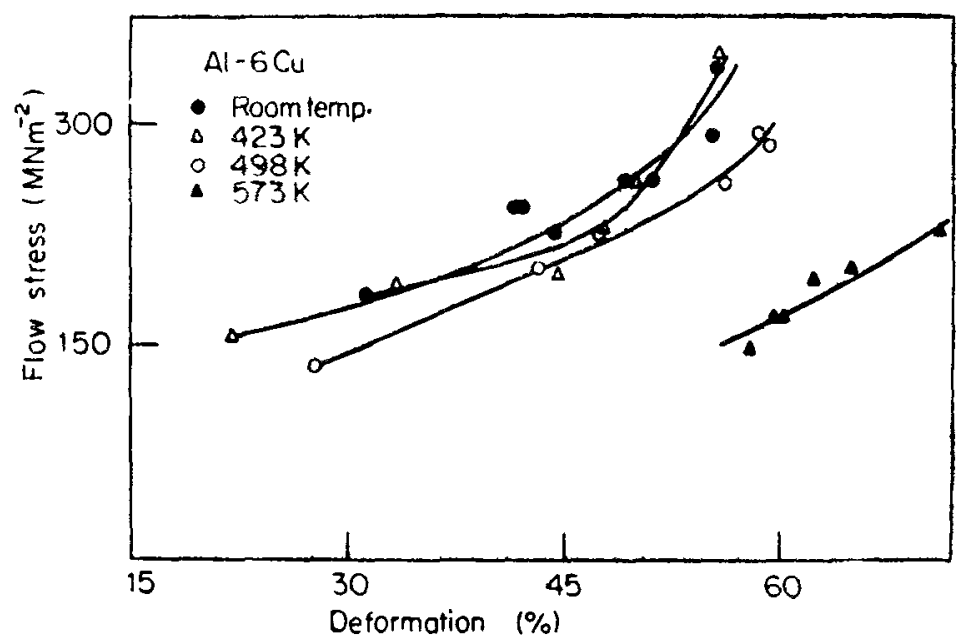

Fig. 3

Figures 1-3. Flow stress values at different incremental deformations and temperature levels, 1. Al-6Cu-As cast, 2. Al-6Cu-Heat treated for 24 hours 3. Al $-6 \mathrm{Cu}-$ Heat treated for 36 hours.

It is seen from figures 4 and 5 that spheroidizing the specimen has resulted in the second phase being less continuous as compared to the as-cast state, at the same temperature and deformation load. Further, as seen from figures 1 and 2 , the flow stress in the spheroidized specimen is lower. When both the deformation load and the temperature are now increased, the redistribution of the second phase continues, but as seen from figure 6 coalescence of the second phase particles seems to take place. The flow stress corresponding to this condition is not much different from that of the as-cast material. Thus the morphology and distribution of the second phase particles as affected by temperature and deformation seem to be important considerations in determining the flow stress of this alloy, in addition to the variations in hardening characteristics of the matrix as affected by the above factors.

\section{Conclusions}

Using the method developed by Saul et al (1971) based on Avitzur's analysis, realistic data on the flow stress of aluminium $-6 \%$ copper alloy have been obtained for different specimen history and temperatures. It has been shown that microstructural features, e.g., morphology and distribution of the second phase particles,

Figures 4-6. 4. Specimen history: As-cast ; Temperature: $150^{\circ} \mathrm{C}(423 \mathrm{~K})$; Deformation load: $50 \mathrm{KN}$. 5. Specimen history: Spheroidized for 24 hours; Temperature : $150^{\circ} \mathrm{C}(423 \mathrm{~K})$; Deformation load : $50 \mathrm{KN}$. 6. Specimen history : Spheroidized for 36 hours; Temperature: $225^{\circ} \mathrm{C}(498 \mathrm{~K})$; Deformation load : $250 \mathrm{KN}$. 


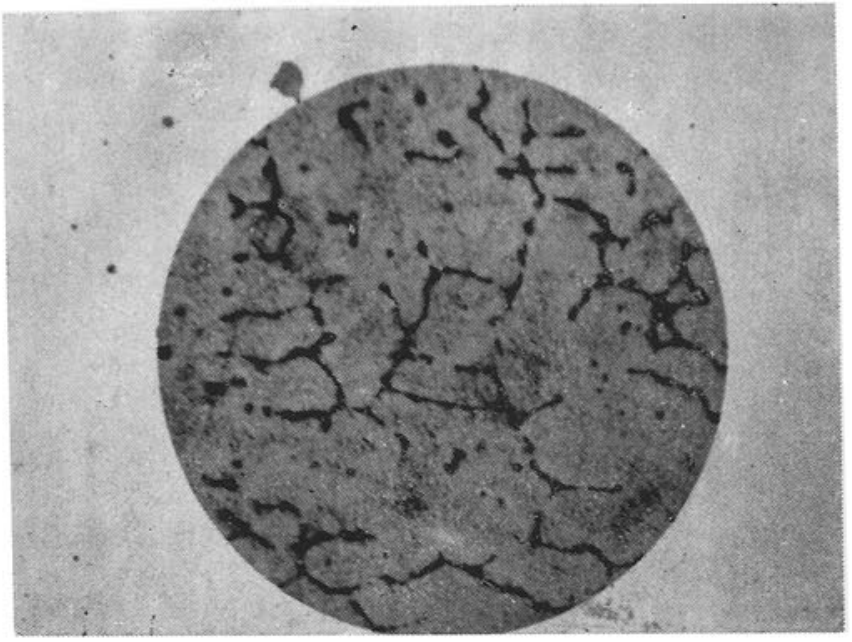

(4)

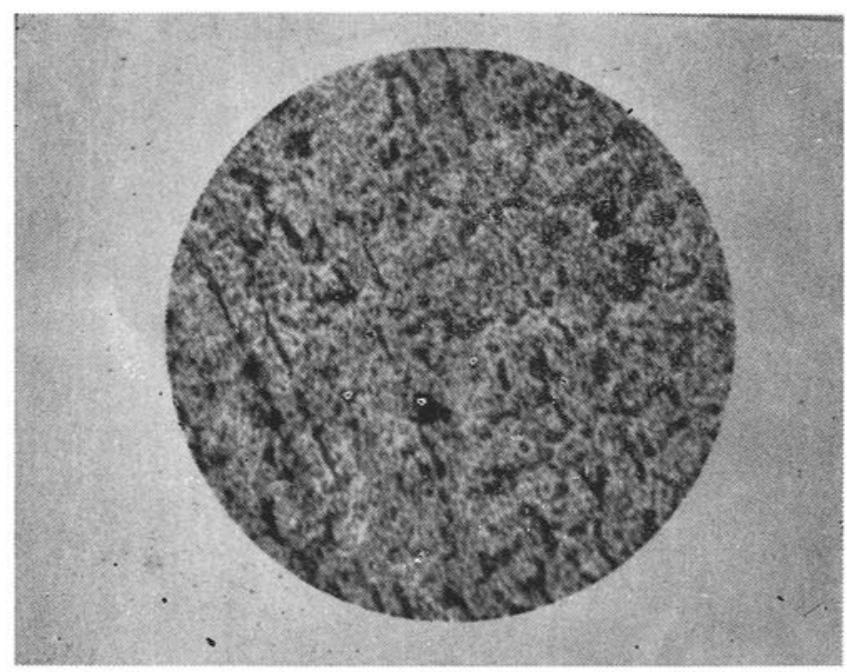

(5)

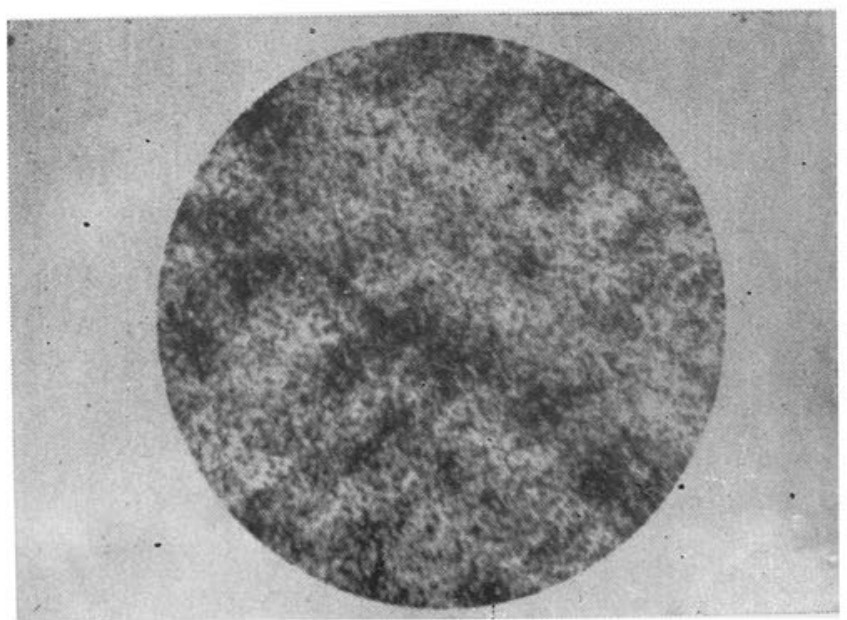

(6) 
are important considerations in determining the flow stress of the alloy under given conditions. When forming this alloy at temperatures below about $500 \mathrm{~K}$ it seems to be advisable to limit the deformation at each stage to about $50 \%$, as the flow stress seems to increase markedly at higher deformations.

\section{Acknowledgements}

The authors would like to thank the Department of Science and Technology, Government of India, for extending financial support to this work.

\section{References}

Berry J T and Pope M H 1971 Metal forming-Interrelation between theory and practice (ed.) A Hofinanner (New York: Plenum) 308

Ashok S and Charles JA 1979 Extended abstracts, Int. Conf. on Fracture mechanics in engineering application, Bangalore, 97

Avitzur B 1968 Metal forming process and analysis (New York: McGraw-Hill)

Saul G, Male A T and Depierre V 1971 Metal forming-Interrelation between theory and practice (ed.) A L Hoffmanner (New York : Plenum) 293

Polakowski N H 1949 J. Iron and Steel Institute 163260 